\title{
Urban-Rural Disparities of Facility-Based Childbirth in Indonesia
}

\author{
Agung Dwi Laksono ${ }^{1 *}$, Ratna Dwi Wulandari², \\ ${ }^{1}$ National Institute of Health Research and Development, the MOH of the Republic of \\ Indonesia. J1. Percetakan Negara 29, Jakarta, Indonesia. \\ ${ }^{2}$ Faculty of Public Health, Universitas Airlangga, Surabaya, Indonesia. \\ *Corresponding Author: \\ Agung Dwi Laksono. Email: agungd11@gmail.com
}

\begin{abstract}
Background: Equitable distribution of health services between areas is still a problem in various countries. Even in developed countries. This condition also applies to the utilization of healthcare facilities for childbirth.

Objective: To analyze the urban-rural disparities of facilities-based childbirth in Indonesia.

Methods: The analysis in this study uses raw data from the 2017 IDHS. With stratification and multistage random sampling, 17,769 women aged 15-49 years with live births in the last 5 years were sampled. Data were analyzed using a Binary Logistic Regression test.

Results: Women in urban areas were probably 2.417 times more utilizing healthcare facilities for delivery than those in rural areas. Women with tertiary education were likely to be 1.709 times more utilizing healthcare facilities for delivery than those who don't. Richest women were probably 6.556 times more utilizing healthcare facilities for delivery than poorest women. Women who have health insurance maybe 1.437 times more utilizing healthcare for delivery than women who don't have. Women who know about the danger signs of pregnancy are more than 1.514 times more likely to utilize healthcare for delivery than those who don't know. Women who do ANC $\geq$ 4 times have the possibility of 1.729 times using healthcare facilities compared to those who do ANC less than 4.

Conclusion: There were significant differences between women in urban and rural areas in utilizing healthcare facilities for delivery. Women who live in urban areas have a better chance to utilize healthcare facilities for delivery. The government needs to focus on women with low education and poor status. Interventions were needed by socializing the danger signs of pregnancy in rural areas. In addition, it was also necessary to expand the scope of membership of the National Health Insurance in rural areas.
\end{abstract}

Keywords: urban-rural, disparities, facility-based childbirth, healthcare evaluation

\section{BACKGROUND}

Equitable distribution of health services between areas is still a problem in various countries. Even in developed countries like the United States, this condition also still occurs. A study found that there are differences in health, access to and quality of healthcare between rural and urban areas in the United States (Anderson et al., 2015)(Zahnd and McLafferty, 2017)(Croft et al., 2018). Several studies in Africa and the European Union also revealed the same thing (Ravit et al., 2018)(Karuaihe and Wandschneider, 2018)(Piotrowska et al., 2018)(Yaya et al., 2019). Thus 
it can be concluded that the disparity in health services between urban and rural areas is still a global problem.

Many factors affect the disparity in access to health services between urban and rural. Some of the reasons include religious fallacy, traditional views, and also limited access of women to decision making in the family, making many rural women not take advantage of modern health services in the delivery process (Sarker et al., 2016)(Greenwood-Ericksen, Tipirneni and Abir, 2017)(Dwiningsih and Laksono, 2019). Other causes are poor road quality and lack of transportation also contribute to the low willingness of women in rural childbirth in health facilities (Jacobs, Michelo and Moshabela, 2018)(Xu et al., 2018).

In general, several studies have found different community characteristics between those who live in urban and rural areas. Among them, the education status of rural communities tends to be lower than that of urban areas, opportunities to access information in rural communities are more limited, more rural communities especially women who are not working, and poverty is predominant in rural (Xu et al., 2018)(Jagnoor et al., 2018)(Weinhold and Gurtner, 2018). Other characteristics are geographical features that tend to be more severe, for example mountainous areas, uneven land contours, large forests, which have an impact on transportation difficulties, which will further strengthen the reluctance of people to go to health care facilities (Lam et al., 2018)(Jarman et al., 2018)(Spees et al., 2019). This is what causes residents to live in rural counties are more likely to have poorer health outcomes along with a variety of measurements that comprise the County Health Rankings' indexed domain of health quality (Anderson et al., 2015).

The choice of place of birth is very important to study, because in areas that have limited access to delivery services in health facilities, tend to be followed by high cases of maternal mortality (Ei et al., 2019)(Macuácua et al., 2019)(Cockcroft et al., 2019). Based on the background, this article was compiled to analyze urban-rural disparities of facility-based childbirth in Indonesia. The results of the study's analysis are useful for policymakers to ensure more equal delivery of services between urban and rural areas.

\section{MATERIALS AND METHODS}

\subsection{Data Source.}

The analysis in this study uses raw data from the 2017 Indonesian Demographic Data Survey (IDHS). The IDHS was part of the International Demographic and Health Survey (DHS) program conducted by the Inner City Fund (ICF). In Indonesia, the 2017 IDHS was carried out by the Central Statistics Agency (BPS), in collaboration with the National Population and Family Planning Board (BKKBN) and the Ministry of Health.

Stratification and multistage random sampling were used in the selection of the 2017 IDHS sample. The 2017 IDHS was conducted in 34 provinces in Indonesia from May to August 2017. The samples used in this study were urban poor women aged 15-49 years old who had given birth in the last 5 years. The sample size of the 2017 IDHS used in this analysis was 17,769 women.

\subsection{Procedure.}

The 2017 IDHS has obtained ethical approval from the National Institute for Health Research and Development of the Indonesian Ministry of Health. The respondents' identities have all been deleted from the dataset. Respondents have provided written approval for their involvement in the study. The use of the 2017 IDHS data for this study has received permission from ICF International through its website: https://dhsprogram.com/data/new-userregistration.cfm. 


\subsection{Data Analysis.}

Childbirth at a health service facility was a delivery at a health center (Puskesmas), clinic or maternity hospital, the practice of health workers and hospitals (Ministry of Health of the Republic of Indonesia, 2015). The 2017 IDHS data was obtained through a structured questionnaire. Variables analyzed included place of residence, age, education level, work status, marital status, parity, wealth status, cover by health insurance, the autonomy of family finances, the autonomy of health, knowledge of pregnancy, knowledge of delivery, and antenatal care.

Statistical analysis using Chi-Square was carried out for dichotomous variables and t-test for continuous variables. This statistical analysis was conducted to assess whether there were differences in childbirth service that were statistically significant between the types of urban and rural areas. Estimates are performed using Binary Logistic Regression because of the nature of the dependent variable. All statistical analyses were carried out using SPSS 19 software.

\section{RESULTS}

The co-linearity test was carried out in the first step, before carrying out the multinomial logistic regression test. Co-linearity test results were shown in Table 1 that there is no co-linearity between the dependent and independent variables.

Table 1. Results for the co-linearity test of Facility-based Childbirth in Indonesia

\begin{tabular}{lcc}
\hline \multirow{2}{*}{ Variables } & \multicolumn{2}{c}{ Collinearity Statistics } \\
\cline { 2 - 3 } & Tolerance & VIF \\
\hline Place of Residence & 0.796 & 1.257 \\
Region & 0.941 & 1.063 \\
Age & 0.585 & 1.709 \\
Education level & 0.708 & 1.412 \\
Work status & 0.944 & 1.060 \\
Marriage status & 0.812 & 1.232 \\
Parity & 0.538 & 1.858 \\
Wealth status & 0.613 & 1.632 \\
Health insurance & 0.959 & 1.042 \\
The autonomy of family finances & 0.805 & 1.242 \\
The autonomy of Health & 0.727 & 1.376 \\
Know the dangers of the pregnancy & 0.900 & 1.111 \\
Antenatal care & 0.876 & 1.142 \\
\hline
\end{tabular}

*Dependent Variable: Place of Delivery

Table 1 showed that the tolerance value of all variables is greater than 0.10 . While the VIF value for all variables is less than 10.00. Then referring to the basis of decision making in the multicollinearity test it can be concluded that there are no symptoms of multicollinearity in the regression model.

Table 2 shows that there are differences between women who use healthcare facilities for delivery in rural and urban areas for all characteristics that are observed to be statistically significant, except for work status and autonomy for family financial. Table 2 informs that women who use healthcare facilities for delivery are more dominant than those who deliver at nonhealthcare facilities. 
Table 2. Descriptive Statistic of Facility-Based Childbirth by Place of Residence in Indonesia

\begin{tabular}{|c|c|c|c|c|}
\hline \multirow{2}{*}{ Characteristics } & \multicolumn{2}{|c|}{ Place of Residence } & \multirow{2}{*}{ All } & \multirow{2}{*}{$\mathbf{P}$} \\
\hline & Urban & Rural & & \\
\hline Place of Delivery & & & & 0.000 \\
\hline - Nonhealthcare Facilities & $1182(13.55 \%)$ & $3788(41.87 \%)$ & $4970(27.97 \%)$ & \\
\hline - Healthcare Facilities & $7541(86.45 \%)$ & $5258(58.13 \%)$ & $12799(72.03 \%)$ & \\
\hline Age (mean) & $8723(31.24)$ & $9046(30.48)$ & $17769(30.85)$ & 0.000 \\
\hline Education level & & & & 0.000 \\
\hline - No education (ref.) & $41(0.47 \%)$ & $228(2.52 \%)$ & $269(1.51 \%)$ & \\
\hline - Primary & $1433(16.43 \%)$ & $2998(33.14 \%)$ & $4431(24.94 \%)$ & \\
\hline - Secondary & $5269(60.40 \%)$ & $4610(50.96 \%)$ & $9879(55.60 \%)$ & \\
\hline - Higher & $1980(22.70 \%)$ & $1210(13.38 \%)$ & $3190(17.95 \%)$ & \\
\hline Work status & & & & 0.112 \\
\hline - No work (ref.) & $4603(52.77 \%)$ & $4881(53.96 \%)$ & $9484(53.37 \%)$ & \\
\hline - Work & $4120(47.23 \%)$ & $4165(46.04 \%)$ & $8285(46.63 \%)$ & \\
\hline Marriage status & & & & 0.001 \\
\hline - Never married (ref.) & $4(0.05 \%)$ & $25(0.28 \%)$ & $29(0.16 \%)$ & \\
\hline - Married/Living with Partner & $8457(96.95 \%)$ & $8755(96.78 \%)$ & $17212(96.87 \%)$ & \\
\hline - Divorced/Widowed & $262(3.00 \%)$ & $266(2.94 \%)$ & $528(2.97 \%)$ & \\
\hline Parity (mean) & $8723(2.39)$ & $9046(2.62)$ & $17769(2.51)$ & 0.000 \\
\hline Wealth status & & & & 0.000 \\
\hline - Poorest (ref.) & $832(9.54 \%)$ & $4101(45.33 \%)$ & $4933(27.76 \%)$ & \\
\hline - Poorer & $1387(15.90 \%)$ & $2083(23.03 \%)$ & $3470(19.53 \%)$ & \\
\hline - Middle & $1836(21.05 \%)$ & $1412(15.61 \%)$ & $3248(18.28)$ & \\
\hline - Richer & $2176(24.95 \%)$ & $946(10.46 \%)$ & $3122(17.57 \%)$ & \\
\hline - Richest & $2492(28.57 \%)$ & $504(5.57 \%)$ & $2996(16.86 \%)$ & \\
\hline Health insurance & & & & 0.000 \\
\hline - No (ref.) & $2955(33.88 \%)$ & $3746(41.41 \%)$ & $6701(37.71 \%)$ & \\
\hline - Yes & $5768(66.12 \%)$ & $5300(58.59 \%)$ & $11068(62.29 \%)$ & \\
\hline The autonomy of family finances & & & & 0.692 \\
\hline - No (ref.) & $2252(25.82 \%)$ & $2359(26.08 \%)$ & $4611(25.95 \%)$ & \\
\hline - Yes & $6471(74.18 \%)$ & $6687(73.92 \%)$ & $13158(74.05 \%)$ & \\
\hline The autonomy of Health & & & & 0.004 \\
\hline - No (ref.) & $1122(12.86 \%)$ & $1296(14.33 \%)$ & $2418(13.61 \%)$ & \\
\hline - Yes & $7601(87.14 \%)$ & $7750(85.67 \%)$ & $15351(86.39 \%)$ & \\
\hline Know the danger signs of pregnanc & & & & 0.000 \\
\hline - No (ref.) & $2534(29.05 \%)$ & $3830(42.34 \%)$ & $6364(35.82 \%)$ & \\
\hline - Yes & $6189(70.95 \%)$ & $5216(57.66 \%)$ & $11405(64.18 \%)$ & \\
\hline Antenatal care & & & & 0.000 \\
\hline$-<4$ times (ref.) & $1782(20.43 \%)$ & $2457(27.16 \%)$ & $4239(23.86 \%)$ & \\
\hline$-\geq 4$ times & $6941(79.57 \%)$ & $6589(72.84 \%)$ & $13530(76.14 \%)$ & \\
\hline
\end{tabular}

Note: Chi-Square test was used for dichotomous variables; T-test for continuous variables.

Table 2 shows that the average person living in urban areas is slightly older than in rural areas. Indonesian women who have given birth in the last five years are also dominated by those who have secondary education and have married/living with a partner, both in urban and rural areas.

Table 2 informs that Indonesian woman who gave birth in the last five years in urban areas had a lower average parity than women who lived in rural areas. In urban areas, Indonesian women 
who have given birth in the last five years are dominated by the richest women, while those in rural areas are the opposite, dominated by the poorest women.

In the category of health insurance ownership, Indonesian women who gave birth in the last five years in both areas were dominated by women covered by insurance. Indonesian women who gave birth in the last five years in both areas were also dominated by those who had autonomy in determining their own health. Indonesian women who gave birth in the last five years in urban and rural areas were dominantly aware of the danger signs of pregnancy, and also dominantly did antenatal care more than 4 times.

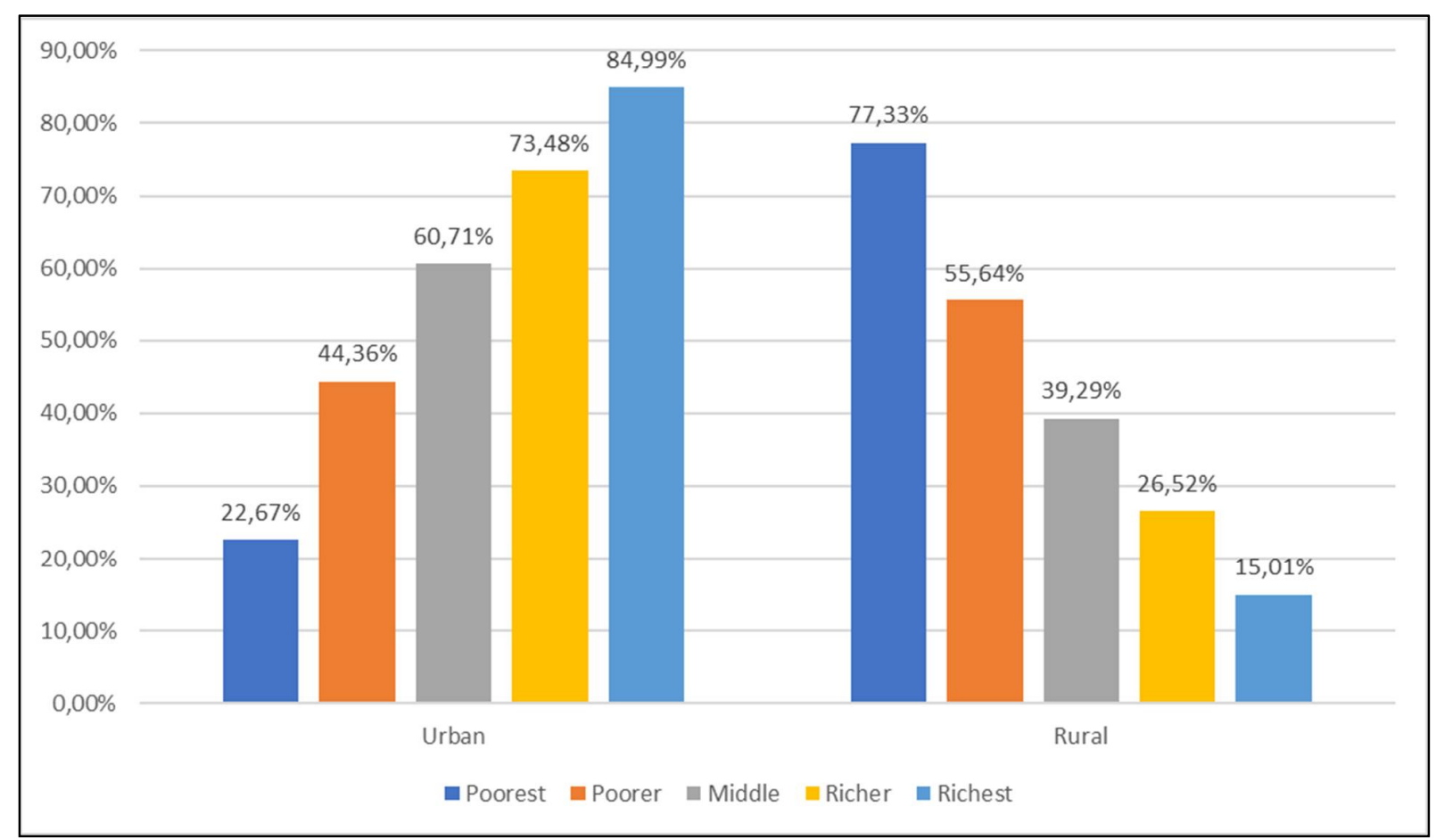

Figure 1. Distribution of women who use the healthcare facilities for delivery in Indonesia

Figure 1 shows that Indonesian women who gave birth the last five years in urban areas, the richest were the most utilizing the healthcare facilities for delivery in Indonesia. The opposite condition applies to women who live in rural areas, the poorest are the most utilizing the healthcare facilities for delivery in Indonesia.

Table 3 displays the results of the binary logistic regression test to illustrate the disparity between the utilization of healthcare facilities for delivery in urban and rural areas. As a reference, the chosen category is "nonhealthcare facilities". Table 3 shows the significant differences between women in urban and rural areas in utilizing healthcare facilities for delivery. Those who live in urban areas are 2.417 times more likely to use healthcare facilities for delivery than those living in rural areas (OR 2.417; 95\% CI 2.219-2.633). Table 3 informs that age and parity in women significantly contribute to the utilization of healthcare facilities for delivery.

Table 3 shows that women with tertiary education are likely 1.709 times more likely to use healthcare facilities for delivery than those without schooling (OR 1.709; 95\% CI 1.249-2.338). While marriage status does not show a significant effect.

Richest women are 6.556 times more likely to use healthcare facilities for delivery than poorest women (OR 6.556: 95\% CI 5.487-7.835). While women who have health insurance are 
1.437 times more likely to use healthcare facilities for delivery than women who are not covered by health insurance (OR 1.437; 95\% CI 1.330-1.551).

Table 3. Binary Logistic Regression of The Place of Delivery in Indonesia $(n=17,769)$.

\begin{tabular}{lccc}
\multirow{2}{*}{\multicolumn{1}{c}{ Predictor }} & \multicolumn{3}{c}{ Healthcare Facilities } \\
\cline { 2 - 4 } & OR & Lower Bound & Upper Bound \\
\hline Place of Residence: Urban & $* * * 2.417$ & 2.219 & 2.633 \\
Age & $* * * 1.038$ & 1.030 & 1.046 \\
Education level: Primary & $* 1.387$ & 1.034 & 1.860 \\
Education level: Secondary & $* * * 1.891$ & 1.409 & 2.537 \\
Education level: Tertiary & $* * 1.709$ & 1.249 & 2.338 \\
Marriage status: Never Married & 0.539 & 0.237 & 1.226 \\
Marriage status: Married/Living with Partner & 0.548 & 0.237 & 1.270 \\
Parity & $* * * 0.789$ & 0.764 & 0.815 \\
Wealth status: Poorer & $* * * 1.901$ & 1.722 & 2.099 \\
Wealth status: Middle & $* * * 2.669$ & 2.383 & 2.990 \\
Wealth status: Richer & $* * * 3.158$ & 2.775 & 3.595 \\
Wealth status: Riches & $* * * 6.556$ & 5.487 & 7.834 \\
Health insurance: Yes & $* * * 1.437$ & 1.330 & 1.551 \\
Autonomy of Health: Yes & 1.012 & 0.897 & 1.141 \\
Know the danger signs of pregnancy: Yes & $* * * 1.514$ & 1.401 & 1.636 \\
Antenatal care: $\geq 4$ times & $* * 1.729$ & 1.585 & 1.885 \\
\hline Note: $* 0.05 ; * p<0.01 ; * * * p<0.001$ & & & \\
\hline
\end{tabular}

Note: $* \mathrm{p}<0.05 ; * * \mathrm{p}<0.01 ; * * * \mathrm{p}<0.001$.

Table 3 informs that the autonomy that women have in determining their own health needs does not show a significant effect on the utilization of healthcare facilities for delivery. While knowledge of the danger signs of pregnancy is proven to be influential. Women who know about the danger signs of pregnancy are 1.514 times more likely to use healthcare facilities for delivery than those who don't (OR1.514; 95\% CI 1.401-1.636).

Table 3 shows that the frequency of antenatal care is also a predictor of the utilization of healthcare facilities for delivery. Women who did antenatal care four or more times during pregnancy were 1.729 times more likely to use healthcare facilities for delivery than those who did antenatal care less than four times (OR 1.729; 95\% CI 1.585-1.885).

\section{DISCUSSION}

The results showed that women who live in urban areas use healthcare facilities for delivery better than women who live in rural areas. This is in line with the results of other studies on urbanrural disparities in the utilization of health service facilities in Indonesia, both in basic services at the Healthcare Center (Wulandari and Laksono, 2019), and referral services in hospitals (Laksono, Wulandari and Soedirham, 2019b), which shows better utilization in urban areas.

Research by taking the theme of disparity between urban and rural areas in several countries also shows consistent results. Not only about the utilization of health services, including access to health information, which shows a disparity between urban and rural areas, including in China (Zhang et al., 2017)(Li et al., 2018), India (Chakrabarti and Tatavarthy, 2019), Iran (Reshadat et al., 2019), Malaysia (Shahar et al., 2019), and Africa (Yaya et al., 2019). 
Generally, development in rural areas in Indonesia tends to be slower than urban areas, including in the health sector. The private sector prefers to participate in development in urban areas. This is because of the denser population density, so it is more profitable economically (Johar et al., 2018)(Dewi and Mukti, 2018). The government must be able to respond to this condition, it needs ongoing evaluation to ensure efforts to minimize the disparity between the two regions, and ensure better access in rural areas (Karuaihe and Wandschneider, 2018)(Dong, 2019)(Laksono, Wulandari and Soedirham, 2019a).

In addition to disparities between urban and rural areas, other predictors of healthcare facilities for delivery utilization found were education level, parity, wealth status, health insurance, knowledge of the danger signs of pregnancy, and frequency of antenatal care. The higher level of education of women is statistically significant in increasing deliveries to health care facilities. In general, the level of education is directly proportional to wealth status and knowledge of the danger signs of pregnancy. The higher the level of education, the better the wealth status, the more understanding about the danger signs of pregnancy, the more will increase the utilization of health care facilities in childbirth (Shahabuddin et al., 2016)(Asseffa, Bukola and Ayodele, 2016)(Efendi et al., 2019).

Various studies in several countries on the impact of ownership of health insurance have found findings that have increased the use of health services that is far better (Lee et al., 2018)(Tilahun et al., 2018)(Miraldo, Propper and Williams, 2018)(Müllerschön et al., 2019). The same conditions apply to Indonesia (Mubasyiroh, Nurhotimah and Laksono, 2016)(Laksono, Wulandari and Soedirham, 2019b). Not only in the use of childbirth services, but also in the use of antenatal care services (Efendi et al., 2019).

\section{CONCLUSIONS}

Based on the results of the study it can be concluded that there is a significant disparity between women in urban and rural areas in the utilization of healthcare facilities for delivery. Women who live in urban areas have better possibilities to utilize healthcare facilities for delivery. The government must focus more on targeting women with low and poor education. Interventions are needed to socialize the danger signs of pregnancy in rural areas. In addition, it is also necessary to expand the scope of membership of the National Health Insurance in rural areas.

\section{ACKNOWLEDGMENTS}

The author would like to thank the ICF International, who has agreed to allow the 2017 IDHS data to be analyzed in this article.

\section{DECLARATION OF CONFLICTING INTERESTS}

The authors declared no potential conflicts of interest with respect to the research, authorship, and/or publication of this article.

\section{ORCID}

Agung Dwi Laksono https://orcid.org/0000-0002-9056-0399

Ratna Dwi Wulandari https://orcid.org/0000-0003-4365-5747

\section{REFERENCES}

Anderson, T. et al. (2015) 'A cross-sectional study on health differences between rural and nonrural U.S. counties using the County Health Rankings', BMC Health Serv Res, 1(15), p. 441. 
doi: 10.1186/s12913-015-1053-3.

Asseffa, N. A., Bukola, F. and Ayodele, A. (2016) 'Determinants of use of health facility for childbirth in rural Hadiya zone, Southern Ethiopia', BMC Pregnancy and Childbirth, 16(1), p. Article number 355. doi: 10.1186/s12884-016-1151-1.

Chakrabarti, S. and Tatavarthy, A. D. (2019) 'The geography of medical travel in India: Differences across states, and the urban-rural divide', Applied Geography, 107, pp. 12-25. doi: 10.1016/j.apgeog.2019.04.003.

Cockcroft, A. et al. (2019) 'The impact of universal home visits with pregnant women and their spouses on maternal outcomes: A cluster randomised controlled trial in Bauchi State, Nigeria', BMJ Global Health, 4(1), p. Article number e001172. doi: 10.1136/bmjgh-2018001172.

Croft, J. B. et al. (2018) 'Urban-rural county and state differences in chronic obstructive pulmonary disease - United States, 2015', Morbidity and Mortality Weekly Report, 67(7), pp. 205-211.

Dewi, A. and Mukti, A. G. (2018) 'The strategy to achieve universal health coverage membership in Indonesia', Research Journal of Pharmacy and Technology, 11(5), pp. 1774-1777. doi: 10.5958/0974-360X.2018.00329.3.

Dong, W. (2019) 'Self-rated health among elders in different outmigration areas-a case study of rural Anhui, China', Journal of Chinese Sociology, 6(1), p. Article number 9. doi: 10.1186/s40711-019-0096-y.

Dwiningsih, S. and Laksono, A. D. (2019) 'How to control the sexually transmitted diseases in Benjina?: qualitative studies on the practice of prostitution', Health Science Journal of Indonesia, 10(1), pp. 58-66. doi: 10.22435/hsji.v10i1.1044.

Efendi, F. et al. (2019) 'Determinants of facility-based childbirth in Indonesia', Scientific World Journal, 2019, p. Article number 9694602. doi: 10.1155/2019/9694602.

Ei, W. L. S. S. et al. (2019) 'Nagaland health assessment: High mortality rates and difficulty accessing essential health services in Lahe Township, Republic of the Union of Myanmar', PLoS ONE, 14(5), p. Article number e0216925. doi: 10.1371/journal.pone.0216925.

Greenwood-Ericksen, M. B., Tipirneni, R. and Abir, M. (2017) 'An Emergency Medicine-Primary Care Partnership to Improve Rural Population Health: Expanding the Role of Emergency Medicine', Annals of Emergency Medicine, 70(5), pp. 640-647. doi: 10.1016/j.annemergmed.2017.06.025.

Jacobs, C., Michelo, C. and Moshabela, M. (2018) 'Implementation of a community-based intervention in the most rural and remote districts of Zambia: A process evaluation of safe motherhood action groups', Implementation Science, 13(1), p. Article number 74. doi: 10.1186/s13012-018-0766-1.

Jagnoor, J. et al. (2018) 'Identifying priority policy issues and health system research questions associated with recovery outcomes for burns survivors in India: A qualitative inquiry', $B M J$ Open, 8(3), p. Article number e020045. doi: 10.1136/bmjopen-2017-020045.

Jarman, M. P. et al. (2018) 'Mapping areas with concentrated risk of trauma mortality: A first step toward mitigating geographic and socioeconomic disparities in trauma', Journal of Trauma and Acute Care Surgery, 85(1), pp. 54-61. doi: 10.1097/TA.0000000000001883.

Johar, M. et al. (2018) 'Inequality in access to health care, health insurance and the role of supply factors', Social Science and Medicine, 213, pp. 134-145. doi: 10.1016/j.socscimed.2018.07.044.

Karuaihe, S. T. and Wandschneider, P. R. (2018) 'Limited access to services for the urban poor in 
Windhoek, Namibia', Development Southern Africa, 35(4), pp. 466-479. doi: 10.1080/0376835X.2018.1475219.

Laksono, A. D., Wulandari, R. D. and Soedirham, O. (2019a) 'Regional Disparities of Health Center Utilization in Rural Indonesia', Malaysian Journal of Public Health Medicine, 19(1).

Laksono, A. D., Wulandari, R. D. and Soedirham, O. (2019b) 'Urban and Rural Disparities in Hospital Utilization among Indonesian Adults', Iranian Journal of Public Health, 48(2), pp. 247-255. Available at: http://ijph.tums.ac.ir/index.php/ijph/article/view/16143.

Lam, H. Y. et al. (2018) 'Describing the health Service Delivery Network of an urban poor area and a rural poor area', Acta Medica Philippina, 52(5), pp. 438-446.

Lee, Y.-H. et al. (2018) 'Growing concerns and controversies to Taiwan's National Health Insurance-what are the lessons from mainland China, South Korea and Singapore?', International Journal of Health Planning and Management, 33(1), pp. e357-e366. doi: 10.1002/hpm.2387.

$\mathrm{Li}$, J. et al. (2018) 'Urban-rural disparities in health care utilization among Chinese adults from 1993 to 2011 ', BMC health services research, 18(102), pp. 1-9. doi: 10.1186/s12913-0182905-4.

Macuácua, S. et al. (2019) 'Policy review on the management of pre-eclampsia and eclampsia by community health workers in Mozambique 11 Medical and Health Sciences 1117 Public Health and Health Services', Human Resources for Health, 17(1), p. Article number 15. doi: 10.1186/s12960-019-0353-9.

Ministry of Health of the Republic of Indonesia (2015) Republic of Indonesia Minister of Health Regulation Number 99/2015 concerning Health Services at National Health Insurance. Indonesia.

Miraldo, M., Propper, C. and Williams, R. I. (2018) 'The impact of publicly subsidised health insurance on access, behavioural risk factors and disease management', Social Science and Medicine, 217, pp. 135-151. doi: 10.1016/j.socscimed.2018.09.028.

Mubasyiroh, R., Nurhotimah, E. and Laksono, A. D. (2016) 'Health Service Accessibility Index in Indonesia (Indeks Aksesibilitas Pelayanan Kesehatan di Indonesia)', in Supriyanto, S., Chalidyanto, D., and Wulandari, R. D. (eds) Accessibility of Health Services in Indonesia (Aksesibilitas Pelayanan Kesehatan di Indonesia). Jogjakarta: PT Kanisius, pp. 21-58.

Müllerschön, J. et al. (2019) 'Impact of health insurance status among migrants from sub-Saharan Africa on access to health care and HIV testing in Germany: A participatory cross-sectional survey 11 Medical and Health Sciences 1117 Public Health and Health Services 11 Medical and Healt', BMC International Health and Human Rights, 19(1). doi: 10.1186/s12914-0190189-3.

Piotrowska, D. E. et al. (2018) 'Socio-economicinequalities in the use of dental care in urban and rural areas in poland', Annals of Agricultural and Environmental Medicine, 25(3), pp. 512516. doi: $10.26444 /$ aaem/89917.

Ravit, M. et al. (2018) 'Do free caesarean section policies increase inequalities in Benin and Mali?', International Journal for Equity in Health, 17(1), p. Article number 71. doi: 10.1186/s12939-018-0789-x.

Reshadat, S. et al. (2019) 'Measures of spatial accessibility to health centers: investigating urban and rural disparities in Kermanshah, Iran', Journal of Public Health (Germany), 27(4), pp. 519-529. doi: 10.1007/s10389-018-0966-9.

Sarker, B. et al. (2016) 'Reasons for Preference of Home Delivery with Traditional Birth Attendants (TBAs) in Rural Bangladesh: A Qualitative Exploration', PLoS One, 11(1), p. 
e0146161. doi: 10.1371/journal.pone.0146161.

Shahabuddin, A. S. M. et al. (2016) 'Determinants and trends in health facility-based deliveries and caesarean sections among married adolescent girls in Bangladesh', BMJ Open, 6(9), p. Article number e012424. doi: 10.1136/bmjopen-2016-012424.

Shahar, S. et al. (2019) 'Health, access and nutritional issues among low-income population in Malaysia: Introductory note', BMC Public Health, 19, p. Article number 552. doi: 10.1186/s12889-019-6852-8.

Spees, L. P. et al. (2019) 'Evaluating the urban-rural paradox: The complicated relationship between distance and the receipt of guideline-concordant care among cervical cancer patients', Gynecologic Oncology, 152(1), pp. 112-118. doi: 10.1016/j.ygyno.2018.11.010.

Tilahun, H. et al. (2018) 'Factors for healthcare utilization and effect of mutual health insurance on healthcare utilization in rural communities of South Achefer Woreda, North West, Ethiopia', Health Economics Review, 8(1). doi: 10.1186/s13561-018-0200-z.

Weinhold, I. and Gurtner, S. (2018) 'Rural - urban differences in determinants of patient satisfaction with primary care', Social Science and Medicine, 212, pp. 76-85. doi: 10.1016/j.socscimed.2018.06.019.

Wulandari, R. D. and Laksono, A. D. (2019) 'Urban-Rural Disparities in The Utilization of Primary Health Care Center Among Elderly in East Java, Indonesia', Jurnal Administrasi Kesehatan Indonesia, 7(2), p. in press.

$\mathrm{Xu}$, Y. et al. (2018) 'General analysis of factors influencing cataract surgery practice in Shanghai residents', BMC Ophthalmology, 18(1), p. Article number 102. doi: 10.1186/s12886-0180767-5.

Yaya, S. et al. (2019) 'Decomposing the rural-urban gap in the factors of under-five mortality in sub-Saharan Africa? Evidence from 35 countries', BMC Public Health, 19(1), p. Article number 616. doi: 10.1186/s12889-019-6940-9.

Zahnd, W. E. and McLafferty, S. L. (2017) 'Contextual effects and cancer outcomes in the United States: a systematic review of characteristics in multilevel analyses', Annals of Epidemiology, 27(11), pp. 739-748.e3. doi: 10.1016/j.annepidem.2017.10.002.

Zhang, X. et al. (2017) 'Urban-rural differences in the association between access to healthcare and health outcomes among older adults in China', BMC Geriatrics, 17(1). doi: 10.1186/s12877-017-0538-9. 